\title{
DESIGN PARA MOBILIARIO ECOEFICIENTE UTILIZANDO PAPELÃO ONDULADO
}

\author{
Annibal Gouvêa Franco \\ UEMG \\ francoartedesign@gmail.com \\ Rosemary do Bom Conselho Sales \\ UEMG \\ rosebcs@gmail.com \\ Nelcy Della Santina Mohallem \\ UFMG \\ nelcy@ufmg.br
}

\begin{abstract}
Resumo: Dada a importância do segmento e produção de celulose e derivados no Brasil e no mundo, e dos problemas ambientais oriundos de seus descartes, pode-se prever que nos próximos anos os problemas ambientais relacionados ao descarte de subprodutos de papel/papelão devem se agravar. Estimativas indicam que este cenário combinado à realização de grandes eventos no Brasil entre 2014 e 2016, deve favorecer uma expansão de aproximadamente $4 \%$ nas vendas de papelão. Neste trabalho foi feito um levantamento da aplicação do resíduo de papelão como material alternativo. O resultado mostra a ação de profissionais no sentido de conseguir produzir mobiliário e objetos ecológicos não convencionais, de baixo custo, de visual atraente e criativo. No entanto, existe uma carência de estudos mais aprofundados, com a finalidade de avaliar a resistência e durabilidade destes materiais para fins estruturais.
\end{abstract}

Palavras-chave: Resíduos de papelão, sociedade de consumo, design ecoeficiente.

Abstract: Due to the importance of the segment and production of pulp in
Brazil and in the world, and due to the environmental problems arising
from their discard, it can be predicted that in the next years the
environmental problems related to the discard of by-products of
paper/cardboard should be aggravated. Estimates indicate that this
scenario combined with the realization of big events in Brazil between
2014 and 2016, should encourage an expansion of approximately $4 \%$ in
sales of cardboard. In this work, it was done a survey of the application of
the cardboard residues as an alternative material. The result shows the
action of professionals to produce unconventional furnishings and 
ecological objects of low-cost, with visual appealing and creative. However, there is a lack of detailed studies in order to assess the strength and durability of these materials for structural purposes.

Keywords: cardboard waste, consumer society, eco-efficient design.

\section{INTRODUÇÃO}

As mudanças ambientais causadas pelo homem em decorrência de suas atividades cotidianas têm impactado de forma significativa o meio ambiente. As inovações e as tecnologias de produção e fabricação, em função do surgimento de novos materiais, possibilitam a disseminação de produtos produzidos e distribuídos em larga escala. Um dos temas ambientais mais discutidos refere-se aos resíduos sólidos que se acumulam nos grandes centros urbanos. A sociedade atual, baseada em uma economia consumista, alimenta esse movimento, sendo responsável pela grande quantidade de resíduos descartados, nem sempre ao final de sua vida útil (BARBIERI, 2006).

Atualmente as embalagens estão se transformando na mais rápida produção de fluxo de lixo do mundo pós-industrializado. A humanidade produziu nos últimos 50 anos mais artefatos que em toda a sua história. Um problema resultante dessa ação é o destino final dado a estes materiais, ditos bens de consumo não duráveis, fato que se constitui em um dos maiores problema ambientais que preocupa tanto a sociedade quanto as autoridades (CARDOSO, 2012; BAUMAN, 2008).

A necessidade de inovação nos processos produtivos, que busca atender a atual demanda de mercado, leva os profissionais a criarem produtos diferenciados e de desejo para o consumidor. Esse fator determinante para o melhor aproveitamento do potencial das empresas vem sendo questionado, na medida em que se torna necessário assumir papeis de liderança e ao mesmo tempo padrões de produção e consumo sustentáveis para atender às necessidades sociais, ao mesmo tempo em que é necessário um gerenciamento ambiental responsável.

Frente a um mercado altamente competitivo, a embalagem torna-se estratégica para a competitividade dos negócios, seja pelo seu caráter prático/estético de compor o produto, seja no que diz respeito à eficiência de envase, proteção, distribuição e venda de produtos (ABRE, 2014). Assim, o design, como atividade multidisciplinar, se coloca não só como agente de criação de novos produtos, mas como importante interveniente nas estratégias de posicionamento quanto a melhor forma de utilizar o potencial da embalagem, de forma a agregar ao produto características bastante particulares.

O papelão ondulado é um material mundialmente utilizado como embalagem, principalmente devido ao fato do material apresentar características únicas tais como: facilidade construtiva, custo reduzido em relação à sua capacidade de contenção, resistência mecânica, térmica, dentre outras. Seu consumo por habitante é significativamente superior ao de embalagens fabricadas com materiais como aço, plástico, vidro e alumínio. Segundo o Compromisso Empresarial para Reciclagem, em 2011 o Brasil fabricou 43,9\% de papelão ondulado com a finalidade de produzir embalagens. Entre os anos de 2006 a 2012 o segmento apresentou um crescimento de 
21\% (CEMPRE, 2014). Dados do Sindicato das Indústrias de celulose/papel/papelão do Estado de Minas Gerais, informaram que o Brasil ocupa o 10 lugar no ranking mundial do setor na produção de celulose, sendo os maiores produtores a China e os Estados Unidos (SINPAPEL, 2014).

Apesar do percentual de reciclagem do setor de papel/papelão (70\% a $80 \%)$, o processo não é simples, pois requer triagem prévia, separação, classificação e controle do material. Durante o processo, se faz necessária a retirada de diferentes contaminantes como matéria orgânica, grampos metálicos, colas, vernizes e tintas do material. (CEMPRE, 2014). O resultado dessa ação gera em média $42 \%$ de rejeito não utilizável. Esses resíduos são destinados aos aterros sanitários ou à incineração, o que resulta em acúmulo de rejeitos e aumento das emissões de $\mathrm{CO}_{2}$. Soma-se a isso o alto consumo de água e energia elétrica demandada no processo de fabricação (GRIMBERG; BLAUTH, 1998).

Percebe-se que reciclar não é fácil e também não é suficiente para minimizar os impactos ambientais causados pelo crescente descarte de papel/papelão em aterros sanitários e lixões. Requalificar, buscar novo sentido e soluções inovadoras que venham minimizar os reflexos negativos da destinação inadequada desses produtos vem se tornando preocupação de profissionais e pesquisadores de todo o mundo. Autores como Manzini e Vezzoli (2008) argumentam que os impactos ambientais causados pelos produtos industriais e por suas embalagens, devem ser combatidos com estratégias avançadas que permitem, se possível, a desmaterialização no consumo destes produtos.

Sabe-se que a procura por desenvolvimento sustentável não é um pensamento atual. Medidas governamentais são tomadas ao longo dos anos para regulamentar as responsabilidades dos envolvidos. No Brasil, a Política Nacional de Resíduos Sólidos Lei 12.305/10, sancionada em agosto de 2010 (BRASIL, 2010), trata das diretrizes relativas à gestão integrada e ao gerenciamento de resíduos sólidos. Um dos pontos relevantes dessa legislação é a responsabilidade sobre os resíduos sólidos gerados em uma produção, que se estende a todas as pessoas físicas ou jurídicas responsáveis direta ou indiretamente por esta geração. Tanto o consumo, quanto a gestão integrada de resíduos estão vinculados aos planos municipais para a disposição adequada dos rejeitos e à premissa do desenvolvimento sustentável nas dimensões econômica, social e ambiental (BRASIL, 2010).

Sobre a fabricação das embalagens, estas devem propiciar a reutilização ou reciclagem. Independentemente do sistema de limpeza urbana e do manejo dos resíduos sólidos existe a obrigatoriedade de se fazer a logística reversa: fabricantes, importadores, distribuidores e comerciantes de agrotóxicos, pilhas e baterias, pneus, óleos lubrificantes, lâmpadas fluorescentes e produtos eletroeletrônicos e seus componentes também devem participar. A logística reversa consiste em um conjunto de ações que visa a coleta e destinação adequada desses rejeitos (BRASIL, 2010).

Tendências mundiais voltadas para as preocupações ambientais estimulam os profissionais de design e de áreas afins a repensar seus conceitos tradicionais quanto às características estéticas e funcionais dos bens. Torna-se necessário desenvolver produtos sob o ponto de vista da sustentabilidade. Uma alternativa mundial poderia ser o reaproveitamento dos resíduos da própria cadeia produtiva para a fabricação de 
novos produtos de baixo impacto ambiental e com potencial sustentável. Segundo Scura (2007), através da inovação no uso de materiais, alguns antes tidos como de qualidade inferior, passam a ser vistos como virtuosos, por sua contribuição e preservação ambiental. Um destes exemplos seria a confecção de móveis de papelão, utilizando restos de embalagem.

\section{DESENVOLVIMENTO}

Neste trabalho foi feito um levantamento da aplicação do resíduo de papelão como material alternativo no Brasil e no mundo, com o objetivo de se conhecer as principais ações dos profissionais no sentido de se utilizar o material a fim de se conseguir produzir mobiliário e objetos ecológicos não convencionais, de baixo custo, com visual atraente e criativo. Este levantamento foi realizado em artigos disponibilizados no site www.periodicos.capes, e em dados disponibilizados pela Associação Brasileira de Embalagens, Sindicato das Indústrias de Celulose, Papel e Papelão do Estado de MG, e Rede Brasil de Design Sustentável. Buscou-se identificar os estudos mais aprofundados, que tiveram como finalidade avaliar a resistência e a durabilidade do papelão para fins estruturais.

\subsection{0 papelão ondulado}

O papelão é o material mais utilizado para armazenagem e transporte de mercadorias. É comercializado em diferentes estruturas podendo ser planos ou ondulados. O papelão ondulado é definido como uma estrutura composta por um ou mais elementos ondulados (miolos) fixados a um ou mais elementos planos por meio de adesivo aplicado no topo das ondas conforme mostrado na Figura1.

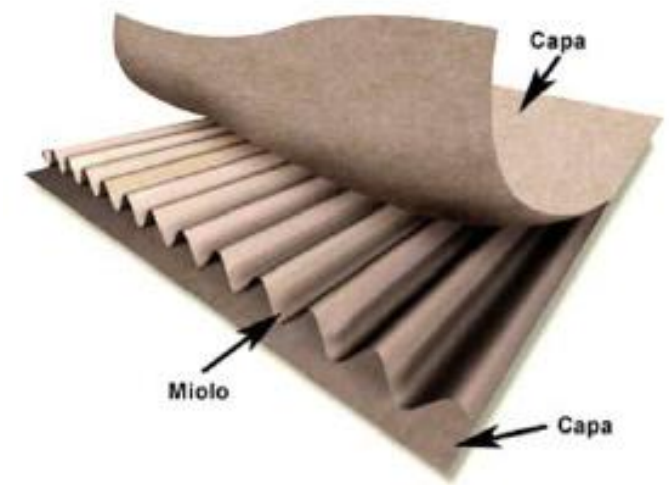

Figura 1 - Estrutura do Papelão Ondulado

FONTE: SANTOS, 2006

Este tipo de papelão é muito versátil, pois pode ser cortado e dobrado em diversos formatos e tamanhos, além de ser extremamente leve, oferecer características de absorção ao choque, ser reciclável e possuir um baixo custo de aquisição se comparado com outras embalagens alternativas (LAGO, 2009). A Associação Brasileira de Normas Técnicas (ABNT) classifica o papelão ondulado e caixas de papelão e sua terminologia, segundo a NBR 5985/2008.

\subsection{Aplicações práticas do papelão ondulado}

A utilização do papelão ondulado na configuração de móveis é recente. A primeira vez que se fez uso do papelão na manufatura industrial foi em 1968, pelo 
designer Peter Raacke, onde a cadeira por ele criada ficou conhecida como Easy Chair Otto (Figura 2).

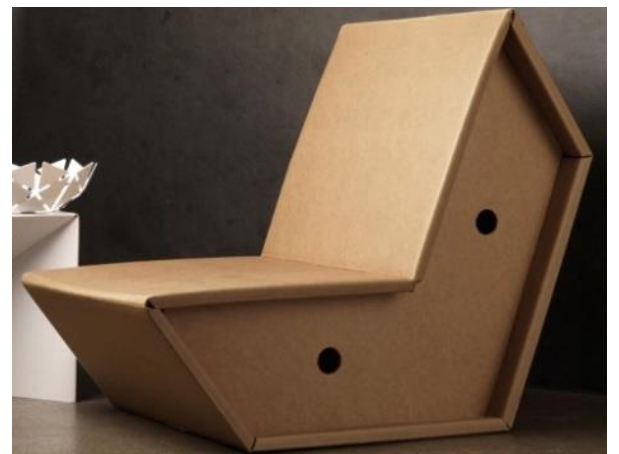

Figura 2 Cadeiras da linha experimental de Frank Gehry, 1987

Fonte: LAGO, 2009

O arquiteto Frank Gehry utilizou o papelão ondulado como matéria-prima para elaboração de móveis e lançou duas linhas de móveis: uma linha que ele chamou de Easy Edges em 1972 (Figura 3), e uma linha experimental em 1987 (Figura 4). Ambas as linhas exploraram as características estruturais e estéticas do papelão. A partir de um produto relativamente simples e comum, o arquiteto produziu industrialmente, móveis leves, robustos e macios, com textura e linguagem formal própria (SANTOS, 2006).

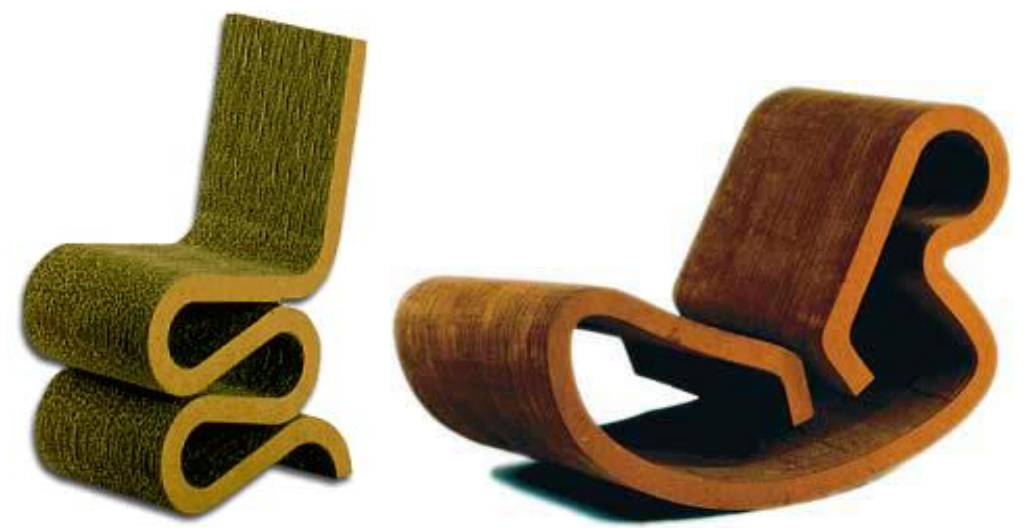

Figura 3 Linha Easy Edges de Frank Gehry, 1972

Fonte: SANTOS, 2006

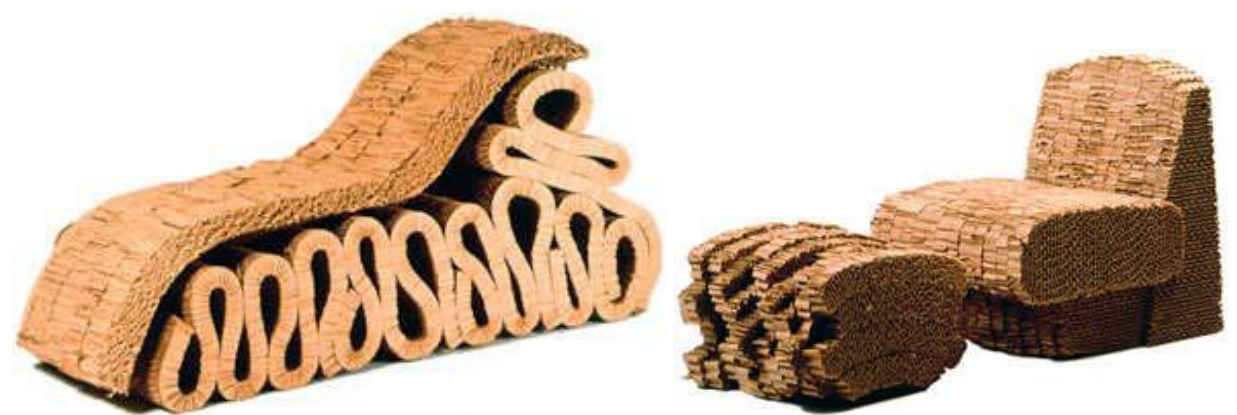

Figura 4 Cadeiras da linha experimental de Frank Gehry, 1987

Fonte: SANTOS, 2006 
Na Suécia, pode-se encontrar no comércio produtos que utilizam o papelão ondulado como matéria prima. A estante irregular Big Chaos (Figura 5) e outros materiais da mesma linha foram fabricados e comercializados pela empresa Retur Design. A empresa se baseia na filosofia ecodesign de repensar, reduzir, reutilizar e reciclar (RRRR).

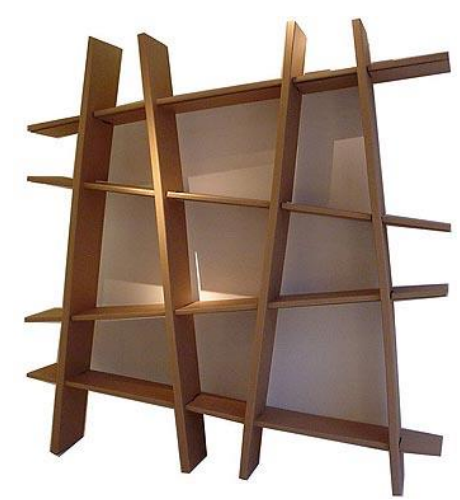

Figura 5: Estante irregular Big Chaos da Retur Design

Fonte: www.returdesign.com

A “Interiors NEC- 2010", de Birmingham no Reino Unido, apresentou uma gama de móveis de papelão ondulado. Dentre eles destaca-se o sofá Radiolaria (Figura 6) de estrutura alveolar como o favo de mel. O móvel inovador surgiu como parte de um projeto colaborativo entre o designer de móveis Liam Hopkins e o artista Richard Sweeney do estúdio Lazerian, em Manchester. A estrutura do móvel, de papelão ondulado reciclado, foi criada por modelamento computacional e teve como inspiração as formas da natureza.
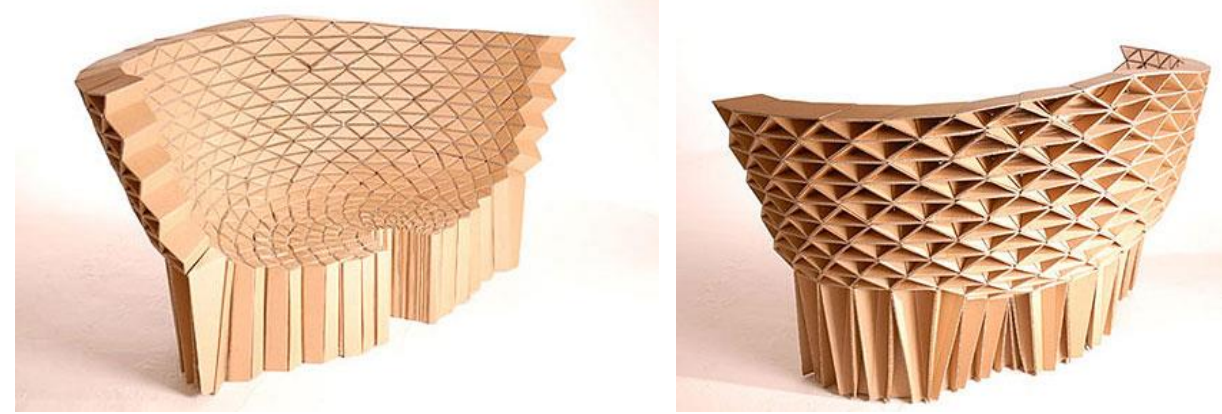

Figura 6 Sofá Radiolaria - Interiors NEC.

Fonte: NEC- 2010 - http://aleal.pt/pt/noticias/4/interiors-nec-birmingham-2010

Os designers holandeses Joost van Bleiswijk e Alrik Koudenburg criaram um mobiliário para escritório em Amsterdã na Alemanha, utilizando como conceito apenas uma caixa de papelão. O conjunto foi inspirado em linhas fortes e clássicas. 0 resultado final foi um projeto inovador composto por 1.500 peças articuláveis, utilizando $500 \mathrm{~m}^{2}$ de papelão, os quais foram fixados e montados sem nenhum tipo de cola ou parafuso (Figura 7). 


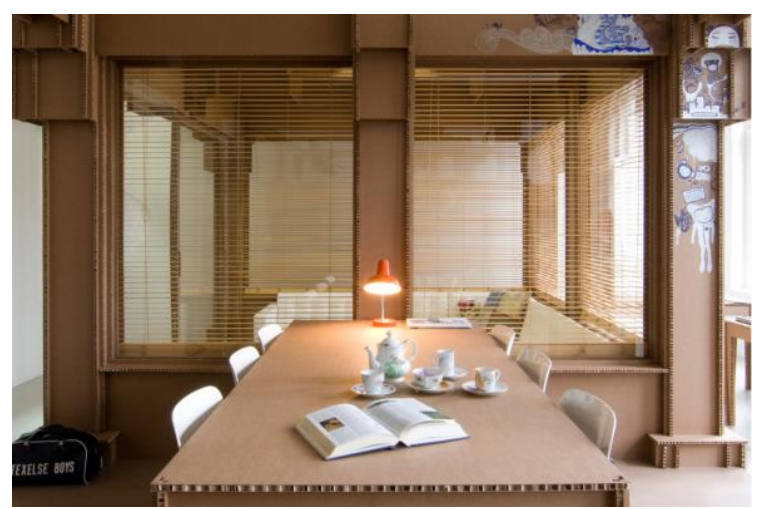

Figura 7 Escritório em Amsterdã

Fonte: www.projectjoost.com

Uma cadeira de papelão $100 \%$ reciclável foi criada por David Graas exclusivamente para crianças, que se chamou de Graas, Finish Your Self (Figura 8). Com ela as crianças podem, não só usar a cadeirinha, mas também se divertir montando o objeto no estilo do faça-você-mesmo. O móvel foi indicado para o prêmio de melhor embalagem através do "Design Awards" Holanda em 2007. A curiosidade é que a cadeira, em grande parte, é derivada da própria embalagem.

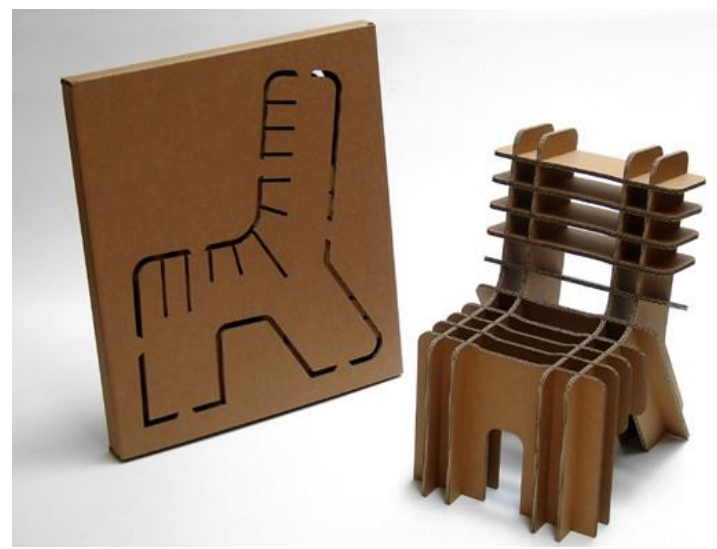

Figura 8 cadeira infantil Graas, Finish Your Self de David Graas

Fonte: www.inhabitots.com

Mesmo que a durabilidade do papelão ainda seja incerta, empresas brasileiras tentam produzir objetos utilizando esse tipo de material. A empresa "100T Inteligente" produz objetos diversos utilizando o papelão ondulado e aposta na facilidade de montagem/desmontagem do produto, no baixo custo e no design inovador (Figura 9). O estúdio de arquitetura e design SuperLimão em São Paulo, desenvolveu a peça de papelão prensado (Figura 10) e buscou aprimorar e aplicar novas técnicas produtivas ao incorporar interessantes tendências estéticas, como o acabamento em PVC expandido, de alta durabilidade, dando ao papelão um ar moderno e atraente. 


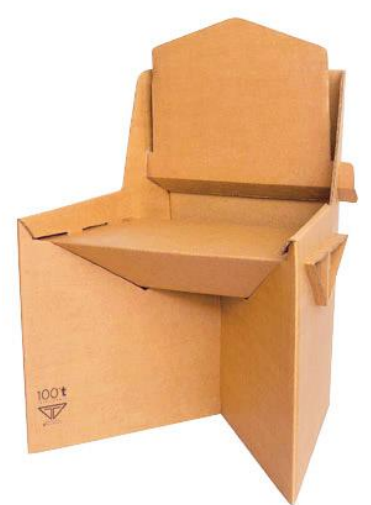

Figura 9: Cadeira Desmontável para adultos.

Fonte: www.100t.com.br

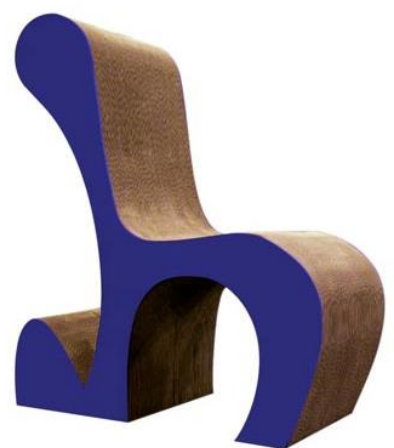

Figura 10: Cadeira com acabamento em PVC da Design SuperLimão

Fonte: www.superlimao.com.br

Estes exemplos mostram as grandes possibilidades de utilização do papelão como móveis, que podem ser confeccionados a partir de material coletado para reciclagem, diminuindo assim a quantidade de resíduos sólidos através do reuso. Apesar desse tipo de móvel ter menor durabilidade, eles podem atender um nicho do mercado baseado em necessidades de móveis para eventos de curta duração, como feiras, congressos, estadias curtas em residências sem móveis, etc. Se eles forem confeccionados a partir de materiais reciclados, não deverão ser contabilizadas perdas ambientais.

\section{CONCLUSÃO}

A lei dos resíduos sólidos vem abrindo novas possibilidades de negócios, onde pequenas empresas se baseiam na coleta de materiais para reciclagem e reuso para produção de novos produtos. A fabricação de móveis de papelão se encaixa neste contexto e tem um grande apelo ecológico, já que projetos que incorporam produtos em sua própria cadeia vêm conquistando espaço no mercado. Fica claro que existe interesse em se utilizar o papelão como material reciclado na sua cadeia produtiva. Através do design é possível agregar valor aos produtos e atingir bom resultado estético e funcional. Existe uma carência de estudos mais aprofundados no sentido de se caracterizar o papelão e avaliar sua resistência e durabilidade, estudos estes que estão em andamento pelos autores deste trabalho. 


\section{REFERÊNCIAS}

CARDOSO, Rafael. Design para um mundo complexo. São Paulo: Cosac Naify, 2012. ISBN: 978-85-405-0098-3.

BAUMAN, Zygmunt, 1925 - Vida para o consumo: a transformação das pessoas em mercadoria; tradução Carlos Alberto Medeiros. - Rio de Janeiro: Zahar, 2008. ISBN 978-85-378-0066-9

MANZINI, E.; VEZZOLI, C. O Desenvolvimento de Produtos Sustentáveis: Os requisitos ambientais dos produtos industriais. Tradução de Astrid de Carvalho. São Paulo: Edusp - Editora da Universidade de São Paulo, 2008. ISBN: 978-85-314-0731-4.

ABNT - ASSOCIAÇÃO BRASILEIRA DE NORMAS TÉCNICAS - NBR 5985/08 Embalagem de papelão ondulado - Terminologia. Rio de Janeiro 2008.

ABRE - ASSOCIAÇÃO BRASILEIRA DE EMBALAGEM - São Paulo. jun. 2010. Disponível em: <http://www.abre.org.br>. Acesso em: 2 fev. 2014.

CEMPRE. Compromisso empresarial para reciclagem. Agora é lei. São Paulo: Política Nacional de Resíduos Sólidos, 2010. Disponível em: <www.cempre.org.br>. Acesso em: 25/11/2014.

SINAPEL - SINDICATO DAS INDUSTRIAS DE CELULOSE, PAPEL E PAPELÃO DO ESTADO DE MINAS GERAIS -Disponível em http://www.sinpapel.com.br. Acesso em 2014.

GRIMBERG, E.; BLAUTH, P. Coleta Seletiva: reciclando materiais, Reciclando valores. Polis: estudos, formação e assessoria em políticas sociais, n.31, 1998.

BRASIL. Lei 12.305, de 02 de agosto de 2010. Institui a Política Nacional de Resíduos Sólidos. Diário Oficial da República Federativa do Brasil, Poder Executivo, Brasília, 3 ago. 2010. Seção 1, p. 3, 2010.

SCURA, R. Design e novos materiais. Inovação Uniemp [online]. 2007, vol.3, n.4, pp. 4041. ISSN 1808-2394.

SANTOS, A. et al. Design em Papelão Ondulado - Série: Design Sustentável Brasil Curitiba: UFPR - Núcleo de Design \& Sustentabilidade, ISBN 85-905660-2-1, 88 p. 2006.

LAGO, T.E.R.; RIBEIRO, M.R.R.; MELO, C.L.; ROMANO. F.V.; BRONDANI, S.A. Estudo do papelão como material alternativo para o design de móveis Anais do $2^{\circ}$ Simpósio Brasileiro de Design Sustentável. Rede Brasil de Design Sustentável. São Paulo. SSN 21762384, Brasil, 2009.

BARBIERI, J. C. Gestão Ambiental Empresarial: conceitos, modelos e instrumentos, São Paulo: Saraiva, 2006. 